\title{
Teaching Revolution Exploration and Practice of the Principles of Automatic Control Course
}

\author{
Bigeng Zheng ${ }^{1, \text { a }}$, Heng Wang ${ }^{2}$, Quanxin Zheng ${ }^{3}$ \\ 1,2,3 School of Electronics and Information Engineering, Jingchu University of Technology, Jingmen \\ 448000, China \\ ${ }^{a}$ begin@jcut.edu.cn
}

Keywords: Automatic control theory, Teaching reform, Teaching system, Teaching methods

\begin{abstract}
Principle of automatic control is a professional basic course with strong theory and engineering practice. It is widely applied in so many engineering disciplines such as aerospace, agriculture, transportation, electrical and mechanical manufacturing. The main task of this course is to train students' ability on the analysis of the control system design, engineering practice ability and innovation ability based on control theory knowledge learning. The main features are: content abstract, theoretical, close contact with math's, wide knowledge, practical engineering, and fast renewal development[2]. It is these characteristics that cause students feel difficult to learn, teachers hard to teach, difficult to guarantee the teaching effect relying on the traditional teaching method and means. This paper focuses on the characteristics of the automatic control principle course and the current problems existing in the teaching process to explore the reform of classroom teaching and experiment teaching ideas and measures so as to fully arouse the enthusiasm of both teachers and students.
\end{abstract}

\section{The brief introduction of automatic control theory}

Principle of automatic control is the most important theories in the study of control subjects, and at the same time is the application foundation of the relating courses such as systematical science, information science, mechanism[1]. It has been widely used in industry, military, social, economic and other fields. As a discipline, automatic control theory belongs to the science and technology, its research object is the automatic control system, the center of the research problem is to control the system in the process of control performance, its content mainly includes the basic concept of classical control theory, the basic principle, basic analysis methods and integrated design method. Automatic control principle course has the following three aspects: first, involving many professionals. The course is professional basic course of automation, electrical engineering and its automation, mechanical design and manufacturing and automation, and also is the basic course of machinery, instruments and meters, power, electrical information. Therefore, the course covers very wide marketability. Second, it is an important professional basic course. Automatic control principle course belongs to the professional foundation (technology) course or subject, on the basis of the teaching time is just learned lesson (technology), to specialized courses, therefore, the design of the teaching process, content, organization, teaching method and so on the effect of a direct impact on students' learning, students affects the subsequent course of study, affects the student to the master of professional knowledge. Third, it is a methodology course. Principle of automatic control course, especially the classical control theory, keeping feedback as the main content, its core idea is "using error to eliminate", change from the qualitative physical system through the establishment of the mathematical model to quantitative method of mathematical analysis, and embodies the information flow, a set of methodology of system theory, control thought, the establishment of the thoughts of methodology in which students study this course is very useful[3].

In order to meet the needs of the development control technology and control theory, and puts forward new requirements for personnel training in the new period, the reform of the automatic control principle teaching should be taken seriously. In the teaching, we should pay attention to the use of advanced teaching method, reasonable use of multimedia and other modern means of 
information technology to improve teaching efficiency and to establish an excellent teaching team, make the teaching quality of the principle of automatic control take a new step.

\section{The present situation and analysis of the course teaching}

According to the actual demand of civil aviation industry, the electronic information engineering college set up "automatic control principle" in 2009[4]. The teaching content based on the linear time-invariant system gives priority to classical control theory involving in the establishment of the control system model, system analysis, system design, the basic theory and related technology. Considering the characteristics of the course itself, specially combines the traditional teaching method with modern teaching method in the teaching practice, gives prominence to the basic concepts and methods of interpretation, and carry out the necessary experiments after class. However, the actual teaching effect is not ideal far from the expectation mainly appearing as the following:

(1) Students are not very active in the classroom teaching, low understanding of concept as well as low the classroom learning efficiency;

(2) Homework plagiarism problem is serious not achieving the purpose of deepening and consolidating learning content;

(3) Lower efficiency of experimental courses, students' enthusiasm is not high, ineffective combination of theory and practice;

All these clearly show that students are not interested in courses above phenomenon, the author carefully analyses the reasons for the above phenomenon: one is to establish the mathematical model of control system involves the theory of knowledge is more, and this part belongs to the first two chapters, and electronic information engineering college students lack early part of the course. Second is a theoretical course itself is strong, require a solid mathematical background, unavoidably feel boring when listening to lectures, as a result, listening to lectures efficiency is low. Third is the existing laboratory equipment ageing, experimental condition has very big limitation, lead students to feel the expected effect experiment, experiment skills can get training. Finally, rarely take the initiative to discuss in class after class between classmates didn't understand the knowledge, and go all the way from the exam-oriented education, learning methods tend to recite and workbook, to do the title as the aim of the study, does not pay attention to understanding and flexible application of knowledge ability is poor. Aiming at these problems, the author from the classroom teaching, homework and examination of three link, take the student as this, fully arouse their learning enthusiasm and initiative, raise the student to the "automatic control principle" course learning interest, thus improve the quality of the course of teaching, to reform as the goal, explore new teaching methods and reform train of thought.

\section{Inspired by interactive teaching and MATLAB aided teaching}

Inspired and interactive teaching, first of all, needs student to obtain knowledge through their own brains, words and activity to stimulate student to learn positively and actively and promote students' positive thinking, play the potential of students, improve the students' ability of comprehensive analysis and application. Secondly through the classroom interaction between teachers and students, so that the students can exchange views keying points and difficulties surrounding content under the guidance of teachers to explore the method to solve the problem[5]. For example in the interpretation of the basic concepts and characteristics of control system, let the student list control technology application in daily life. List for instance, to discuss how to use the block diagram to visually describe the basic principle of how to target specific instances of different modeling method is adopted to establish the mathematical model. It can effectively stimulate the students' positive and active learning, promote students' positive thinking, play the potential of students, improve the students' ability of comprehensive analysis and application.

After each chapter summary, the teacher can take time to design a comprehensive question, let the student work in class discussion to cultivate students' cooperation spirit, improve the students' 
independent and self-control ability and stimulate students' creativity. For example, in the interpretation of the method of frequency analysis, the design of active network circuit system, as shown in Fig. 1. Students are required to draw the block diagram of system and solving the system of open loop and closed loop transfer function, the steady-state error of the calculation system of different input signal, and frequency method is used to analysis the stability of the system. Through the comprehensive discussion on problem sets can not only let the students can master and apply the knowledge of this chapter point to solve the actual problem, also can cultivate student's ability to achieve mastery through a comprehensive study has been to learn knowledge. At the same time, it can also arouse the enthusiasm of the students' consciousness of team work and learning, improve the students' knowledge induction, summary and expression ability, good teaching effect can be obtained.

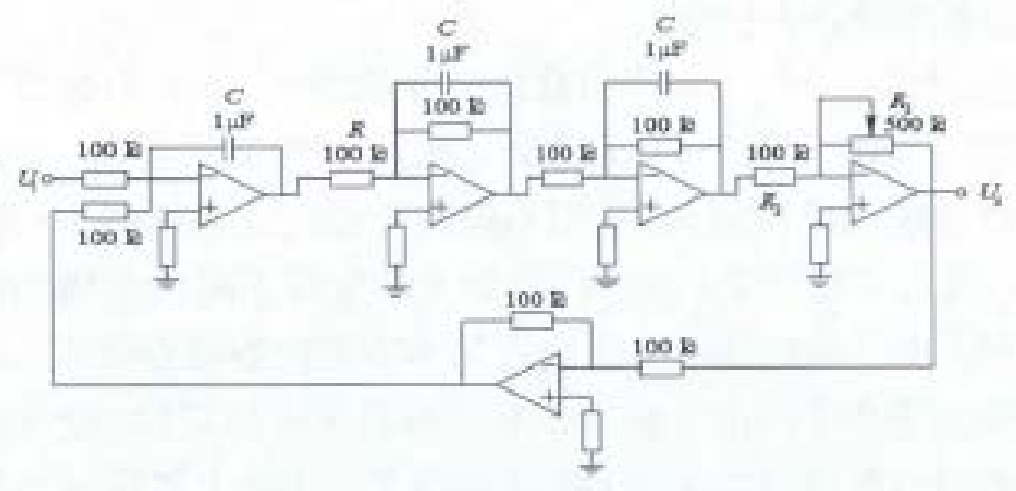

Fig. 1 the active network circuit system

Based on the characteristics of this course, meet the requirements of teaching under the new situation needs to add teaching tools in the course of teaching computer such as the Simulink module in the MATLAB software, which uses dynamic play to make students learn some abstract and difficult theories and concepts more easily. To make the students more deeply know and master the complex and difficult theory and method through the analysis of the control system of concrete movement process in the design of graphic observation and analysis; to make students better grasp how to use computer auxiliary tool for the analysis and design of the control system through the actual presentation in class, so that teachers need to make full use of the teaching process, use the existing good simulation software platform, namely the Simulink module of MATLAB software, in view of the specific control system (as shown in Fig. 2 inertia and lag link control system), introducing the P controller, PI controller and PID controller, by changing the parameters of the controller, simulation results of the control system of observation and comparison of different typical controller will affect the performance of the system so as to make the students several typical controller realize this directly affect of the transient and steady state of the performance of control system, which is helpful to understand, learn and design for the control method of improving system performance.

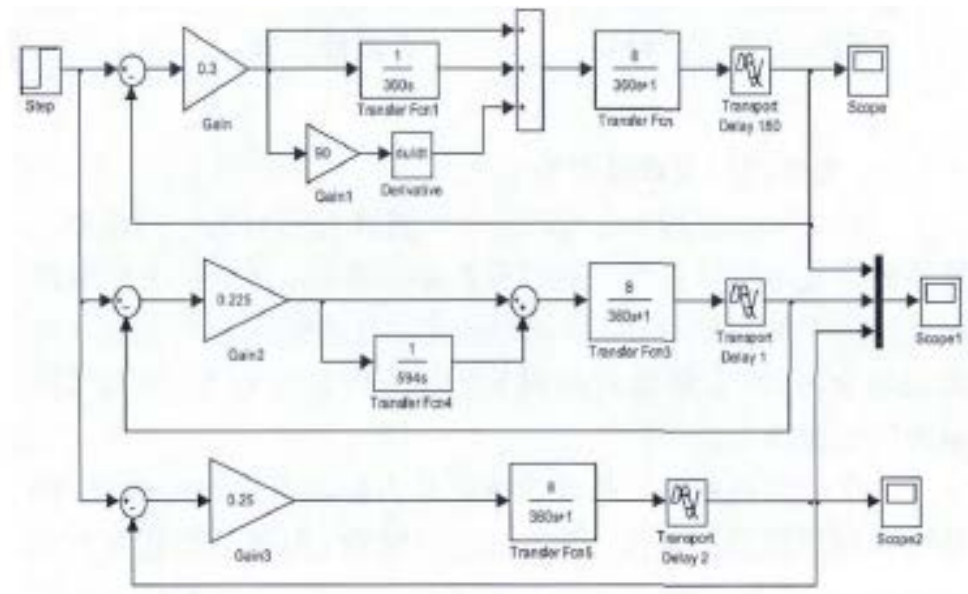

Fig. 2 Inertia and lag link control system 


\section{The research and practice of course teaching methods}

4.1 Adding true examples. Teaching of "Automatic control principle” course cannot be separated from examples and problem explaining. In the face of the abstract transfer function without any physical meaning, the students can't produce controlled object in their mind and controller physical concept and concept of engineering. Therefore, the author uses all the examples of using engineering examples when making courseware from modeling analysis in order to make students understand what is control, how to control, how is the control effect, etc. Instance selection principle used in classroom teaching is: close to everyday life, close to the professional direction, tracking the latest technology. Used in the teaching practice to deepen the process of teaching students the concept of closed loop control (controller, controlled object, accused of quantity and amount of feedback, local feedback, etc.) and the understanding deviation control principle and process, students are more willing to accept, also easy to accept.

Also, for the teaching content of each chapter selecting appropriate examples, such as in the second chapter introduces the control system model of selecting the spread of infectious diseases for instance modeling process, in $3 \sim 5$ learn control system analysis method on the highway speed control system performance analysis, aircraft autopilot pitching Angle control system modeling and analysis to make a research on the satellite antenna control system of wind antenna error influence and so on. All these examples can expand students' vision and train of thought, make them feel learning theoretical knowledge is not dry, abstract formula, but penetration in various areas of the actual physical system.

4.2 Emphasis on content system. Although "Automatic control principle" course is with strong theoretical, many systematic analysis methods, but the course itself is a complete curriculum system inn accordance with the requirements of teaching outline, can draw curriculum system structure. The first requirement of the course is accurate understanding of basic concepts, the precondition of system analysis and design of the control system is establishment of a reasonable model, analysis methods: time domain analysis and root locus analysis and frequency domain analysis, one of the core content of the course. These three analysis methods are corresponding to the mathematical model of the system in different domain, the analysis results by performance indicators, said the performance index can complete system design based on expectations.

\section{Summary}

Automatic control principle course is a course with strong theoretical and wide knowledge. Teachers need to adjust the teaching content according to actual situation in the teaching process and use as many kinds of teaching means and methods, reform experimental teaching and examination methods as they can. Practice shows that reform actually enhances the pertinence and flexibility of teaching, mobilizes the students' interest in learning, improves the students' engineering consciousness and ability in practice, and achieves good teaching effect.

\section{Acknowledgements}

Research on Provincial Teaching Reform in Hubei Province in 2016.

"Study on the school enterprise docking and integration of Electrical Engineering Specialty in local colleges and universities”, Project number:2016423.

\section{References}

[1] C.Y. Tang. Inquiry research and teaching practice of the principle of automatic control course [J]. Journal of electrical and electronics teaching, 2007, 29 (6): 91-93.

[2] Q.M. Meng. Automatic control principle [M]. Beijing: Higher education press, 2008.

[3] X.K. Fang. Wang Jianhui, Zheng Yan, etc. Exploration and practice of teaching reform of "Automatic control principle"[J]. Journal of scientific decision-making, 2008, (11): 101-102. 
[4] X. Mei, Y.M. Luo and M.J. Xia. Course construction of Automatic Control Principle based on the MATLAB [J]. Journal of electrical and electronics teaching, 2005, 27 (2): 22-24.

[5] X.D. Yuan. Teaching reform and practice of Automatic control principle course [J]. Journal of Yichun university (natural science), 2006, 28 (6) : 67-69.

[6] L.P. Zhang. Several realizations of improvement of the quality of the principle of automatic control theory teaching [J]. Journal of higher education BBS, 2004, (1): 70-72. 